\title{
Study on the Utilization of Grape Varieties for Squash Preparation
}

\author{
K. Vanajalatha* and D. Manohar Prasad \\ Post Harvest Research Station, SKLTSHU, Rajendranagar, Hyd-30, Telangana, India \\ *Corresponding author:
}

\section{Keywords}

Grape varieties,

Juices, Squash,

Organoleptic

evaluation

Article Info

Accepted:

04 December 2018

Available Online:

10 January 2019

\section{A B S T R A C T}

In food processing industry blending is an art to develop different colours, aroma, astringency, taste to suit the requirement. Grape squash is a healthy drink both for children and adults. Grape juice has all good quality present in grape wine. Considering nutritional value and to prevent post harvest losses the present investigation was carried out with the objective to explore the compatibility and acceptability of grape squash by blending four varieties of grapes i.e. PusaNavarang, Concord, H23 and Banglore Blue in different proportions (1:1 and 1:2) with 8 treatments. The grape squash with $1: 1$ and $1: 2$ combinations analysed for juice recovery percentage, product recovery percentage, TSS, Acidity, Ascorbic acid and reducing sugars was done for estimating its quality parameters and Organoleptic characteristics (flavor, taste, colour, appearance, consistency and overall acceptability) was tested using 9.0 hedonic scale. The treatment PusaNavarang+Concord T3 (1:1 ratio) had the highest product recovery percentage $(79.10 \%)$. Thus, as for as product acceptability judged by organoleptic evaluation the treatment can be rated as $\mathrm{T} 3>\mathrm{T} 1>\mathrm{T} 5>\mathrm{T} 4>\mathrm{T} 6>\mathrm{T} 8>\mathrm{T} 7>\mathrm{T} 2$. Blending of juices from high yielding varieties with those of juice varieties having good quality can increase value addition for grape.

\section{Introduction}

India is the $2^{\text {nd }}$ largest producer of fruits. One of the most popular among the regularly featuring table fruits are grapes. These berries are store house of numerous health promoting phytonutrients such as polyphenolic antioxidants, vitamins, and minerals. The demand for healthy foods has been one of the most important trends of food consumption in recent years (Bigliardi and Galati, 2013). People are increasingly aware on their own health, as well as the social and environmental impacts of their food consumption (Falguera et al., 2012). Grape (Vitis vinifera) is basically a sub-tropical crop. However, in India, grapes are cultivated for their excellence also under tropical conditions. In India, Grapes are cultivated in an area of 136 million ha with a total production of 2683.3 metric tonnes and productivity of 19.7tons/ha (NHB, 2016-17). In Telangana it is cultivated in an area of 0.32 million ha with a total production of 9.24 metric tonnes (NHB, 2016-17).

In India about 20 million tonnes of foods are produced annually. But hardly $1.2 \%$ of this is utilised for processing and preservation and 
about $30-33 \%$ of the total production is wasted due to spoilage during handling, transportation and lack of cold storage facility (Baisya, 1980). In order to minimize postharvest losses and to avoid market glut, fruits are needed to be effectively utilised in processing industry (Sahota and Sunil, 2006). Approximately 71\% of world grape production is used for wine, $27 \%$ as fresh fruit, and $2 \%$ as dried fruit. Hence, many products like jam, jelly, squash, RTS, syrup etc., are made from fruits. Fresh squashes are becoming popular compared with synthetic beverages because of refreshing quality, taste, flavor, nutritive value and storage stability of fresh squashes (Jothi et al., 2014). Squash is quite popular all over the world as nutritious soft drinks (Babasaheb, 2000). Squash, a ready to drink beverage, is nonalcoholic concentrated syrup that is usually made from fruit juice, water and sugar or sugar substitutes (Joseph and Shukla, 2015).

The squash importance is its nutritional content and delicious flavor. The grape squash contains vitamin $\mathrm{A}$, vitamin $\mathrm{C}$ and potassium. Wild range of juice varieties belonging to Vitis venifera and Vitis labrusca and their hybrids are available. Grapes can be utilized for preparations of squashes and they are in small scales in many parts of the country. But the specific variety is not standardized for specific value added product for its quantity and quality traits after their preparation.

In present work blending of four varieties of grape juices with $1: 1$ and $1: 2$ ratios from high yielding varieties with those of juice from varieties having good quality can increase the value addition for grape squashe.

\section{Materials and Methods}

The experiment was conducted in the laboratory of the Post Harvest Technology Research Station, Rajendranagar, Hyderabad 500030. The fresh and well graded fully ripened four varieties of grapes i.e., Pusa Navarang, Banglore Blue, Concord and H23 were collected from Grape Research Station, Rajendranagar.

The eight treatments i.e., PusaNavarang + Banglore Blue (1:1 ratio) (T1), Pusa Navarang + Banglore Blue (2:1 ratio) (T2), PusaNavarang + Concord (1:1 ratio) (T3), PusaNavarang + Concord (2:1 ratio) (T4), $\mathrm{H} 23$ + Banglore Blue (1:1 ratio) (T5), H23 + Banglore Blue (2:1 ratio) (T6), $\mathrm{H} 23+$ Concord (1:1 ratio) (T7) and $\mathrm{H} 23$ + Concord (2:1 ratio) (T8) were taken for the analysis with three replications and the experimental design was completely randomized design (CRD).

\section{Extraction of grape juice}

Fresh and fully ripe grapes were used for extraction of juice. Grapes were washed thoroughly with water. Grape juice, sugar, citric acid and sodium benzoate required were separately weighed. Water was also measured with measuring cylinder. Grape bunches were weighed and juice was extracted using a high quality electric juicer. The extracted juice was strained properly to remove the seeds. Sugar and citric acid were mixed with water and heated to prepare syrup. Filtered the syrup through a coarse cloth and then cooled. Measured juice was then mixed with the cool syrup. Then sodium benzoate @ of $2 \mathrm{~g} / 1$ was also added. It was mixed thoroughly and finally squash was prepared. It was then poured in sterilized bottle and capped finally.

Squash was analyzed for quality TSS, titrable acidity and ascorbic acid was determined by adopting AOAC (2005) method. Reducing sugars was determined through method illustrated by Ranganna (2011). Sensory properties initially and periodically all treatments of squash were evaluated by a panel of 15 panelists. 
All the panelists were briefed before evaluation. Sensory attributes like appearance and color, aroma, taste and overall acceptability for all samples were assessed using nine point hedonic scales (Larmond, 1977). Organoleptic analysis or sensory evaluation was a scientific discipline that analyses and measure human response to the composition of food or product made by sense of taste, smell, touch and hearing when food eaten.

\section{Results and Discussion}

The data recorded was analyzed. The significant differences observed within and between the treatment combinations. The results showed in table 1 that there was significant difference among the treatments. Maximum juice quantity recorded in T2PusaNavarang + Banglore Blue (2:1 ratio) $(420 \mathrm{ml}$ ) followed by T6 H23 + Banglore Blue (2:1 ratio) $(410 \mathrm{ml})$ and the minimum juice quantity was recorded in $\mathrm{T} 7 \mathrm{H} 23$ + Concord (1:1 ratio) $(215 \mathrm{ml})$. Juice quantity of the fruit vary depends up on the weight of the fruit, peel weight, fibre content and seed weight.

The data pertaining to juice recovery percentage of blended grape juices with different ratios are noticed. Highest juice recovery percentage in $\mathrm{T} 5 \mathrm{H} 23+$ Banglore Blue (1:1 ratio)(73.75 \%), followed by $\mathrm{T} 1$ PusaNavarang + Banglore Blue $(1: 1$ ratio)(69.50\%), T6 H23 + Banglore Blue (2:1 ratio) $(68.33 \%)$ and the lowest juice recovery percentage in T7 H23 + Concord (1:1 ratio)(53.75\%). Similar observations reported by Chaudhary et al., (2014) in Blending of Grape (Vitis vinifera L.) and Jamun (SyzygiumcuminiiL. Skeels) Juices.Juice recovery percentage depends up on the juice weight to total fruits weight.

Significantly maximum amount of reducing sugars in grape juice was noticed in $\mathrm{T} 7 \mathrm{H} 23+$ Concord (1:1 ratio)\&T8H23 + Concord $(2: 1$ ratio) $(15.13 \%)$ and minimum amount of reducing sugars was noticed in $\mathrm{T} 1$ PusaNavarang + Banglore Blue (1:1 ratio) and T2 Pusa Navarang + Banglore Blue (2:1 ratio) $(10.64 \%)$. Whereas, the data pertaining to reducing sugars of blended grape squashes with different ratios are presented in table 2 showed the highest amount of reducing in $\mathrm{T} 7 \mathrm{H} 23$ + Concord (1:1 ratio) and $\mathrm{T} 8 \mathrm{H} 23$ + Concord (2:1 ratio) (1.7\%) and minimum amount of reducing in T1 Pusa Navarang + Banglore Blue (1:1 ratio) and T2PusaNavarang + Banglore Blue (2:1 ratio) $(0.6 \%)$. Similarly reported by Kiranmai et al., (2015).This might be due to variation in concentration of different varieties of grape juice blending.

Significant differences were observed in ascorbic acid content among the treatments. Maximum amount of ascorbic acid in grape juice was recorded in $\mathrm{T} 7 \mathrm{H} 23+$ Concord $(1: 1$ ratio) and $\mathrm{T} 8 \mathrm{H} 23$ + Concord (2:1 ratio) $(11.13 \mathrm{mg} / 100 \mathrm{~g})$ and it was noticed minimum in $\mathrm{T} 5 \mathrm{H} 23+$ Banglore Blue (1:1 ratio)\& $\mathrm{T} 6 \mathrm{H} 23+$ Banglore Blue (2:1 ratio) $(8.79 \mathrm{mg} / 100 \mathrm{mg})$. Similar results about the changes of ascorbic acid in litchi and pomegranate juice blends were reported by Pathak et al., (2012). While, the data presented in table 2 indicated highest amount of grape squash ascorbic acid in $\mathrm{T} 7 \mathrm{H} 23+$ Concord (1:1 ratio) and T8 H23 + Concord $(2: 1 \mathrm{ratio})(4.5 \mathrm{mg} / 100 \mathrm{mg})$ and it was minimum in T5H23 + Banglore Blue (1:1 ratio) and T6 $\mathrm{H} 23$ + Banglore Blue (2:1 ratio) (1.5 $\mathrm{mg} / 100 \mathrm{mg})$. Highest Product recovery percentage is observed in T3 (79.1 \%) followed by T1 $(78.97 \%)$, T5 $(78.30 \%)$ and lowest in $\mathrm{T} 2(63.50 \%)$.

There is no significant difference was observed in TSS, acidity of grape squash and juices blend in different ratios. Similar results were reported by Saikia et al., (2002) in outenga fruit squash (Fig. 1 and 2). 
Table.1 Quality parameters of grape juice prepared with different combinations

\begin{tabular}{|c|c|c|c|c|c|c|c|c|}
\hline Treatments & $\begin{array}{c}\text { Fruit. } \\
\text { wt } \\
\text { (grms) }\end{array}$ & $\begin{array}{c}\text { Quantity } \\
\text { of Juice } \\
\text { (ml) }\end{array}$ & $\begin{array}{c}\text { Juice } \\
\text { recovery } \\
(\%)\end{array}$ & $\begin{array}{l}\text { T.S.S } \\
\left({ }^{0} \text { Brix }\right)\end{array}$ & $\begin{array}{l}\text { Acidity } \\
(\%)\end{array}$ & $\begin{array}{c}\text { Reducing } \\
\text { sugars } \\
(\%)\end{array}$ & $\begin{array}{c}\text { Ascorbic } \\
\text { Acid } \\
\text { (mg/100g }\end{array}$ & $\begin{array}{c}\text { Product } \\
\text { Recovery } \\
\%\end{array}$ \\
\hline $\begin{array}{c}\text { T1: PusaNavarang }+ \text { Banglore Blue } \\
\text { (1:1 ratio) }\end{array}$ & 400 & 278 & 69.50 & 20.9 & 0.10 & 10.64 & 9.54 & 78.97 \\
\hline $\begin{array}{c}\text { T2: PusaNavarang + Banglore Blue } \\
(2: 1 \text { ratio) }\end{array}$ & 600 & 420 & 60.00 & 20.9 & 0.10 & 10.64 & 9.54 & 63.50 \\
\hline $\begin{array}{c}\text { T3 :PusaNavarang + Concord } \\
\text { (1:1 ratio) }\end{array}$ & 400 & 236 & 59.00 & 21.6 & 0.11 & 12.80 & 10.20 & 79.10 \\
\hline $\begin{array}{c}\text { T4:PusaNavarang + Concord } \\
\text { (2:1 ratio) }\end{array}$ & 600 & 380 & 63.33 & 21.6 & 0.11 & 12.80 & 10.20 & 77.90 \\
\hline T5: H23 + Banglore Blue (1:1 ratio) & 400 & 290 & 73.75 & 20.2 & 0.12 & 13.60 & 8.79 & 78.30 \\
\hline T6: H23 + Banglore Blue (2:1 ratio) & 600 & 410 & 68.33 & 20.2 & 0.12 & 13.60 & 8.79 & 67.60 \\
\hline T7: H23 + Concord (1:1 ratio) & 400 & 215 & 53.75 & 20.6 & 0.13 & 15.13 & 11.13 & 66.80 \\
\hline T8: H23 + Concord (2:1 ratio) & 600 & 345 & 57.50 & 20.6 & 0.13 & 15.13 & 11.13 & 67.20 \\
\hline C Dat $5 \%$ & & 23.349 & 5.16 & N.S & N.S & 0.288 & 0.434 & 2.417 \\
\hline SE(d) & & 10.920 & 2.25 & & & 0.135 & 0.203 & 1.130 \\
\hline SE(m) & & 7.72 & 1.204 & & & 0.095 & 0.144 & 0.799 \\
\hline
\end{tabular}


Table.2 Quality parameters of grape squash prepared with different combinations

\begin{tabular}{|c|c|c|c|c|}
\hline Treatments & $\begin{array}{c}\text { T.S.S } \\
\left({ }^{0} \text { Brix }\right)\end{array}$ & $\begin{array}{c}\text { Acidity } \\
(\%)\end{array}$ & $\begin{array}{c}\text { Reducing sugars } \\
(\%)\end{array}$ & $\begin{array}{l}\text { Ascorbic Acid content } \\
(\mathbf{m g} / \mathbf{1 0 0 g})\end{array}$ \\
\hline T1:PusaNavarang + Banglore Blue (1:1 ratio) & 42.30 & 0.40 & 0.60 & 2.70 \\
\hline T2: PusaNavarang + Banglore Blue (2:1 ratio) & 42.30 & 0.40 & 0.60 & 2.70 \\
\hline T3: PusaNavarang + Concord (1:1 ratio) & 44.10 & 0.50 & 0.70 & 4.50 \\
\hline T4: PusaNavarang + Concord (2:1 ratio) & 44.10 & 0.50 & 0.70 & 4.50 \\
\hline T5: H23 + Banglore Blue (1:1 ratio) & 41.30 & 0.60 & 0.90 & 1.50 \\
\hline T6: H23 + Banglore Blue (2:1 ratio) & 41.30 & 0.60 & 0.90 & 1.50 \\
\hline T7: H23 + Concord (1:1 ratio) & 42.10 & 0.70 & 1.70 & 4.50 \\
\hline T8: H23 + Concord (2:1 ratio) & 42.10 & 0.70 & 1.70 & 4.50 \\
\hline C Dat $5 \%$ & N.S & N.S & 0.290 & 1.080 \\
\hline $\operatorname{SE}(d)$ & & & 0.096 & 0.357 \\
\hline SE(m) & & & 0.135 & 0.505 \\
\hline
\end{tabular}


Fig.1 Flow chart for preparation of grape squash

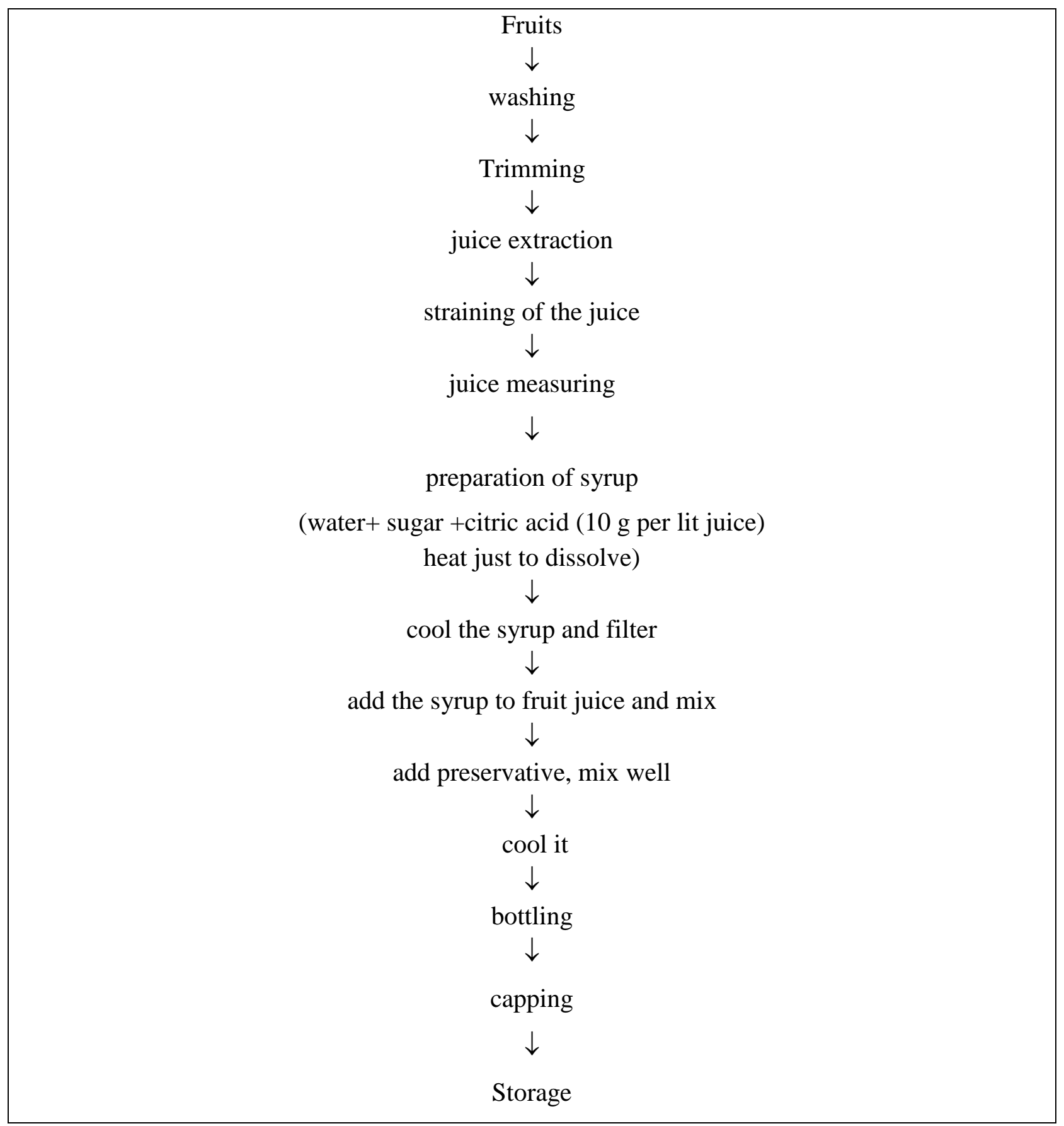


Fig.2 Different varieties selected for squash preparation

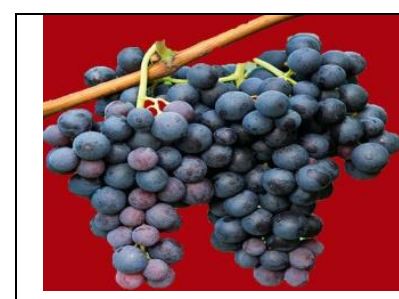

CONCORD

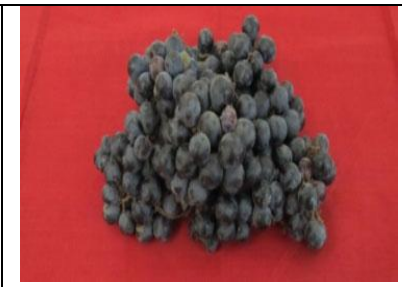

H-23

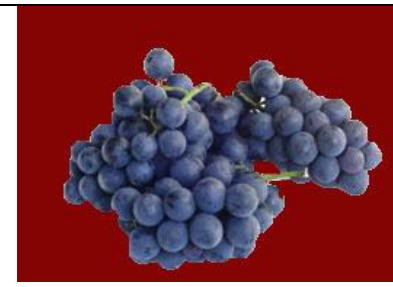

PUSA NAVARANG

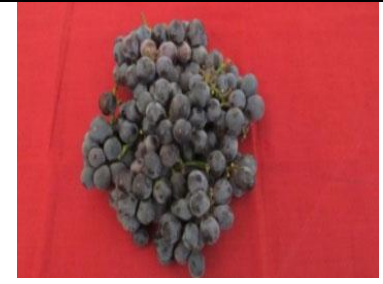

BANGLORE BLUE
In conclusion, the present study showed that blended grape juices in 1:1 and 1:2 ratios could enhance the nutritional quality of squash and development of the new products with improvement in taste, colour and aroma. Eight treatment combinations were followed for the preparation and quality evaluation of grape squash. It was observed that acceptability was more for grape squash when juices were blended in $1: 1$ (Pusa Navarang+Concord) ratios due to highest product recovery percentage with enhanced taste and colour. Considering nutritional value and perishable nature of grapes it can be better utilized for preparation of grape squash by blending of juices provide a product with different taste, flavor and aroma, this process can be further used for production of grape squash. On the basis of the results revealed in the present study it may be concluded that the formulation of blend juice beverage is possible to satisfy consumer taste and preferences.

\section{Acknowledgement}

Authors are thankful to PHTRS, Rajendranagar and SKLTSHU, Hyderabad, for providing the necessary facilities to carry out this research work.

\section{References}

A.O.A.C. 2005.Association of Official Agricultural Chemists. Official Methods of Analysis. Washington, D.C.

Babasaheb, B D. 2000. Hand book of nutrition and diet. Taylor and Francis Inc, New York, United States. Pp 231233.

Baisya, R K. 1980. Fruits and vegetable processing Industries in Rural India- Its problem and prospects. Indian Food Packer. 34(6): 29-32

Bigliardi, B. and Galati, F. 2013. Innovation Trends in Food Industry. The Case of Functional Foods. Trends in Food Science and Technology. 31:118-129.

Chaudhary, C, Yadav B S. and Grewal R B. 2014. Preparation of Red Wine by Blending of Grape (Vitis vinifera L.) and Jamun (Syzygium cuminii L. Skeels) Juices Before Fermentation. International Journal of Agriculture and Food Science Technology. Volume 5(4): 239-348

Falguera, V, Aliguear, N. and Falgure, M. 2012. An integrated approach to current trends in food consumption. Moving towards functional and organic products. Food Control. 26(2): 274-281.

Jothi, J S, Karmoker and Pand Sarower, K. 2014.Quality assessment of mixed fruit squash. Physico chemical analysis, sensory evaluation and storage studies. Journal of Bangladesh Agricultural University. 12(1):195-201

Joseph, J. and Shukla, S. 2015.Preparation and Quality evaluation of mixed fruit squash. International Journal of Advance Industrial Engineering. 393: 1- 
5.

Kiranmai, E, Uma Maheswari, K. and Vimala, B. 2015. Squash from tamarind pulp by blending with mango pulp. Beverage and Food World. 42(2):56-58. Larmond, E.1997. Laboratory methods for sensory evaluation of foods. Department of Agriculture Publication ottava, Canada.

National Horticulture Board. 2016-17. Indian Horticulture Data base. Ministry of Agriculture, Government of India.

Pathak. S, Pandey A. and Gupta A. 2012. Change in quality parameter of blended beverages (RTS + Nectar) during storage. Environment and Ecology
30(4): 1226-1228.

Ranganna, S. 2011. Handbook of analysis and quality control for fruit and vegetable products (second edition). Tata McGraw - Hill publishing company limited. New Delhi: pp 9-10.

Sahota P P, Sunil. 2006. Preparation of non alchoholic naturally carbonated plum Beverage after optimizing the fermentation conditions. Beverage and Food World. 339(2):54-58.

Saikia, L. and Saikia, J. 2002. Processing of ou-tenga (Dillenia indica) fruit for preparation of squash and its quality changes during storage. Journal of food science technology 39(2):149-151.

\section{How to cite this article:}

Vanajalatha, K. and Manohar Prasad, D. 2019. Study on the Utilization of Grape Varieties for Squash Preparation. Int.J.Curr.Microbiol.App.Sci. 8(01): 433-440.

doi: https://doi.org/10.20546/ijcmas.2019.801.045 